doi: $10.15407 /$ ujpe61.10.0923

Y.M. BARABASH, M.A. DRAPIKOVSKYI, M.A. ZABOLOTNY, M.P. KULISH, O.P. DMYTRENKO

Taras Shevchenko National University of Kyiv

(2, Prosp. Academician Glushkov, Kyiv 03022, Ukraine)

\title{
INVESTIGATION OF THE KINETICS \\ OF PHOTOINDUCED ELECTRONIC TRANSITIONS IN NANOSTRUCTURES OF BACTERIAL
} PACS 78. 78. 15.+e REACTION CENTERS

\begin{abstract}
We have studied the slow dynamics of isolated complexes of chlorophyll-containing membrane proteins of photosynthetic reaction centers (RCs) of $R b$. sphaeroides $R$-26 induced by light fluxes. The analysis of a variation of the absorption of a solution of RCs in the frame of the three-level model is carried out. The equation defining the ratio of the populations of the electron levels of the primary and secondary quinones is deduced. The solution of this equation has non-Boltzmann character even in the stationary case and depends on the exciting light intensity. A model of the dynamics of levels of $R C$, which accounts for the presence of polarization processes in a vicinity of the secondary quinone acceptor $\left(\boldsymbol{Q}_{B}\right)$ is proposed. It is assumed that all RCs have the same structure, but can be in different states, whose characteristics depend on both the time interval having passed after the absorption of a light quantum and the local viscosity and elasticity of the environment of $\boldsymbol{Q}_{B}$. The presence of deformational properties of the environment of $\boldsymbol{Q}_{B}$ yields the possibility for a configuration of $R C$ to be changed, which agrees with the experimental data.
\end{abstract}

Ke ywords: biophysics, bacterial reaction centers, electron kinetics, models.

\section{Introduction}

It is known that the absorption of a quantum of light in the reaction centers (RCs) of purple bacteria $R b$. sphaeroides $\mathrm{R}-26$ causes the photooxidation of the primary donor of an electron, a bacteriochlorophyll dimer $(\mathrm{P})$. Thereafter, the excited electron appears at the primary $\left(\mathbf{Q}_{A}\right)$ quinone acceptor, passes through a number of intermediate carriers, and then gets into the terminal quinone acceptor $\left(\mathbf{Q}_{B}\right)$ [1-3]. The process of localization of an electron at quinone acceptors is defined by the state of intrapro-

(C) Y.M. BARABASH, M.A. DRAPIKOVSKYI,

M.A. ZABOLOTNY, M.P. KULISH,

O.P. DMYTRENKO, 2016

ISSN 2071-0194. Ukr. J. Phys. 2016. Vol. 61, No. 10 tein hydrogen bonds (which are formed, in particular, with the participation of water molecules of a solution) and the protonation of the nearest amino acid residues by ionogenic groups and is accompanied by a conformational rearrangement of the molecular complex of RC [2-5]. The information about regularities defining the character of light-activated structural transitions of biomolecules is of independent interest. The conformation determines the bioactivity of a molecule, and the control over structural transitions opens a possibility to use them in molecular electronics.

Despite the great number of publications devoted to the study of photoinduced processes running in $\mathrm{RCs}$, there are the great number of obscurities in 
their theoretical comprehension. Far from being completed is the development of a model allowing the adequate description of the intramolecular dynamics of an electron under the action of exciting light. The complications arising in this case are caused by both the great number of stages of the process of electron transfer inside the complex of $\mathrm{RC}$ and the variety of the transition channels for an electron inside RC. In the simple case, it is considered that RC can be represented in the form of a protein matrix containing some built-in molecules (redox-cofactors), which manifest the donor-acceptor properties relative to the light-excited electron. The electron leaves the donor, a bacteriochlorophyll dimer, appears at the primary quinone $\mathbf{Q}_{A}$, passes a distance of 30 $40 \AA$ through a number of intermediate states, and is stabilized at the secondary quinone-acceptor $\mathbf{Q}_{B}$, by generating, in this case, the difference of potentials on a photosynthetic membrane. The displacement of the electron induced by exciting light can be described [5] in the frame of the three-level model with the level of acceptor $\mathbf{Q}_{B}$, which slowly varies in the process of electron transfer. A change of the energy level of $\mathbf{Q}_{B}$ is defined by structural transitions in $\mathrm{RC}$ and polarization processes in its environment. A change of the energy characteristics of $\mathrm{RC}$ must lead to a change of the rate constants of photoinduced electron transitions. At the present time, the kinetics of these most important characteristics of $\mathrm{RC}$ is studied slightly. The posed problem $[2,5]$ concerning the electron transport in $\mathrm{RC}$ is complicated, and, therefore, the additional simplifying assumptions are used in its analysis [2, 5]. Two of such assumptions are the quasiequilibrium behavior of the ratio of the electron populations on quinones $\mathbf{Q}_{A}$ and $\mathbf{Q}_{B}$ and the independence of this ratio of the intensity of exciting light. The conditions for these assumptions to be valid require the additional analysis.

A goal of the present work is the development of a model of the processes defining structural photoinduced changes in the molecular complex of RC. It is assumed that all molecules of RCs are the same and differ from one another only by the stages of lightstimulated changes. We took the influence of the intensity light on the ratio of the electron populations of $\mathbf{P}, \mathbf{Q}_{A}$, and $\mathbf{Q}_{B}$ into account. As the objects of investigations, we chose the transition rate constants in $\mathrm{RC}$.

\section{The Three-Level Model of the Dynamics of an Electron in RC}

The structural transitions can be registered either directly (on the use of X-ray diffraction or photoluminescence analysis) or mediately with the help of interferometric, photoacoustic, or optical methods [2, $5,6,7]$.

In what follows, we will analyze only the questions concerning the electron transport dynamics in $\mathrm{RC}$ by studying the dynamics of the optical absorption spectrum at the wavelength $\lambda_{0}=865 \mathrm{~nm}$ [1-7]. The possibility of such an approach is caused by the dependence of the interaction cross-section of photons with wavelength $\lambda_{0}$ on the electronic state of the complex of $\mathrm{RC}$, which is changed under the action of the illumination of a specimen containing RCs by exciting light with intensity $I$ and wavelength $\lambda_{0}$. When the electron leaves the bacteriochlorophyll dimer, the $\mathrm{RC}$ losses the ability to absorb the light with wavelength $\lambda_{0}$. In this connection, a change of the absorption $(\Delta A)$ of a specimen is proportional to a change of the probability $p(t)$ of the presence of an electron on the bacteriochlorophyll dimer $[2,5]$ at the time moment of the observation $t$ :

$\Delta A(t) \sim p(t)$.

Relation (1) implies [5] that the rate constant $\left(k_{21}\right)$ of the return of electrons onto $\mathbf{P}$ (donor) from acceptors $\left(\mathbf{Q}_{A}, \mathbf{Q}_{B}\right)$ can be determined by the relation

$k_{21}(t)=-\frac{1}{A(t)-A(0)} \frac{\Delta A(t)}{\Delta t}$.

We now write the system of equations [5] describing the electron transfer in such a system. By $q_{A}(t)$, we denote the probability of the presence of an electron on the primary quinone acceptor $\mathbf{Q}_{A}$; and let $q_{B}(t)$ be the probability of the presence of an electron on the terminal quinone acceptor $\mathbf{Q}_{D}$. Then the following relations are valid:

$$
\begin{aligned}
& \frac{d p(t)}{d t}=-k_{p A} p(t)+k_{A P} q_{A}(t)+k_{B P} q_{B}(t) ; \\
& \frac{d q_{A}(t)}{d t}=k_{P A} p(t)+k_{B A} q_{B}(t)-k_{A P} q_{A}(t)- \\
& -k_{A B} q_{A}(t) ; \\
& \frac{d q_{B}(t)}{d t}=k_{A B} q_{A}(t)-k_{B A} q_{B}(t)-k_{B P} q_{B}(t) .
\end{aligned}
$$

ISSN 2071-0194. Ukr. J. Phys. 2016. Vol. 61, No. 10 
Here, $k_{i j}$ is the transition rate constant between the levels $i \rightarrow j$. The processes running in the molecule of $\mathrm{RC}$ are initiated by exciting light, and, therefore, the parameter $k_{P A}$ depends (is proportional to) on the intensity of exciting light $I$.

The system of equations (3) should be supplemented by the relation

$p(t)+q_{A}(t)+q_{B}(t)=1$

testifying to the closedness of the RC system.

Values of the quantities $k_{i j}$ (except for $k_{P A}$ ) for RC are given in the literature $[2,5]$. It is known that the transition rate constants have the following orders of magnitude: $k_{A P} \sim 10 \mathrm{~s}^{-1}, k_{B P} \sim(0.02-0.2) \mathrm{s}^{-1}$, $k_{A B} \sim 10^{4} \mathrm{~s}^{-1}, k_{B A} \sim 10^{3} \mathrm{~s}^{-1}$. The analysis of the system of equations (3) (without its solution) allows us to obtain the essential information significant for the comprehension of specific features of the functioning of RCs.

We now determine the ratio of the populations of an electron on $\mathbf{Q}_{A}$ and $\mathbf{Q}_{B}$, namely,

$f(t)=\frac{q_{A}(t)}{q_{B}(t)}$.

The use of this quantity allows us to write

$$
\begin{aligned}
& \frac{d q_{B}(t)}{d t} f(t)+q_{B}(t) \frac{d f(t)}{d t}=k_{P A} p(t)+k_{B A} q_{B}(t)- \\
& -\left(k_{A P}+k_{A B}\right) f(t) q_{B}(t) .
\end{aligned}
$$

Substituting the last of Eqs. (3) in (6), we get

$\left[k_{A B} f(t)-k_{B A}-k_{B P}\right] q_{B}(t) f(t)+q_{B}(t) \frac{d f(t)}{d t}=$

$=k_{P A} p(t)+k_{B A} q_{B}(t)-\left(k_{A P}+k_{A B}\right) f(t) q_{B}(t)$

which yields

$$
\begin{aligned}
& {\left[k_{A B} f(t)-k_{B A}-k_{B P}\right] f(t)+\frac{d f(t)}{d t}=} \\
& =k_{P A} \frac{p(t)}{q_{B}(t)}+k_{B A}-\left(k_{A P}+k_{A B}\right) f(t) .
\end{aligned}
$$

It follows from (8) that, even in the stationary case, the ratio of the electron populations of the levels of $\mathbf{Q}_{B}$ and $\mathbf{Q}_{A}$ in the presence of the exciting illumination is not described by the Boltzmann relation, but depends on the intensity $I$. The ratio of the populations of an electron at $\mathrm{Q}_{A}$ and $\mathrm{Q}_{B}$ acquires an especially simple form in the absence of the exciting light $\left(k_{P A}=0\right)$. Then we have

$\frac{d f(t)}{d t}=k_{B A}+\left(k_{B A}+k_{B P}-\right.$
$\left.-k_{A P}-k_{A B}\right) f(t)-k_{A B} f^{2}(t)$

In order to solve Eq. (8), it is necessary to set a value of $f(t)$ at a certain (initial) time moment. It is natural to choose it as the time moment of the switching-out of light. Therefore, in the region of transient time moments, the function $f(t)$ depends on the exciting light intensity, even when the illumination is switchedout. Equation (9) is the exact consequence of the equations of balance (3) of the three-level system and the condition of closedness of system (4). The analysis performed by us with the account for the abovepresented transition rate constants showed that if we do not consider the time interval $\left(0-10^{-3}\right) \mathrm{s}$, then Eq. (9) can be replaced by its stationary linear version,

$0=k_{B A}+\left(k_{B A}+k_{B P}-k_{A P}-k_{A B}\right) f(t)$,

which yields

$f(t)=\frac{k_{B A}}{k_{A P}+k_{A B}-k_{B A}-k_{B P}} \approx \frac{k_{B A}}{k_{A B}}$.

Relation (11) coincides with that in [5], but it can be used only in the study of the processes running in $\mathrm{RC}$, when the illumination is switched-out. While deducing the approximate relation (11), we used the above-given data on the transition rate constants for $\mathrm{RC}$. The use of (11) allows us to write

$q_{A}(t)=\frac{k_{B A}}{k_{A B}} q_{B}(t)$.

We now use (12) in the analysis of both Eq. (4) and the first equation in (3) written in the case where the exciting light is absent $\left(k_{P A}=0\right)$. Then we get

$$
\begin{aligned}
& \frac{d p(t)}{d t}=k_{A P} q_{A}(t)+k_{B P} q_{B}(t)=k_{A P} \frac{k_{B A}}{k_{A B}} q_{B}(t)+ \\
& +k_{B P} q_{B}(t)=\left(k_{A P} \frac{k_{B A}}{k_{A B}}+k_{B P}\right) q_{B}(t)= \\
& =\frac{k_{A P} k_{B A}+k_{A B} k_{B P}}{k_{A B}} q_{B}(t) \\
& p(t)+\frac{k_{B A}}{k_{A B}} q_{B}(t)+q_{B}(t)= \\
& =p(t)+\frac{k_{B A}+k_{A B}}{k_{A B}} q_{B}(t)=1
\end{aligned}
$$


We now account for that RCs are characterized by $k_{A B} \sim 10^{4} \mathrm{~s}^{-1} \gg k_{B A} \sim 10^{3} \mathrm{~s}^{-1}$. Hence, relation (14) can be replaced by

$p(t)+q_{B}(t)=1$,

which allows us to write Eq. (13) in the form

$\frac{d p(t)}{d t}=\frac{k_{A P} k_{B A}+k_{A B} k_{B P}}{k_{A B}}(1-p(t))$.

Equation (16) together with the initial condition

$p(t=0)=p_{0}$

describe the kinetics of the RC system after the switching-out of exciting light. The parameter $p_{0}$ in (17) is determined by the population of the donor of electrons at the time moment of the switching-out of light. Relations (16) and (17) give possibility to describe RC as a two-level system on the time intervals more than $0.001 \mathrm{~s}$. In this case, the rate constant $k_{21}$ of the transition of an electron from the acceptor (which is a dynamical combination of $\mathbf{Q}_{A}$ and $\mathbf{Q}_{B}-$ level 2) to donor $\mathbf{P}$ (level 1) is determined by the relation

$k_{21}=\frac{k_{A P} k_{B A}+k_{A B} k_{B P}}{k_{A B}}$.

Thus, while studying the relaxation dynamics of the absorption of a solution of RCs to within the times of at least $0.001 \mathrm{~s}$, we can use the equation

$\frac{d p(t)}{d t}=k_{21}(1-p(t))$.

The rate constant of the return of an electron to the donor, $k_{21}$, is given by relation (18). As the initial condition, we use representation (17). Thus, the quantities $k_{21}$ and $p_{0}$ are the unique characteristics, which can be determined from the experiments [see formula (2)] on studying the relaxation of the absorption of a solution of $\mathrm{RCs}$, which arises after the termination of its exposure with exciting light.

The repetition of the executed analysis in the case where $I \neq 0$ shows that the kinetics of the electron population of $\mathrm{P}$ can be described by the equation

$\frac{d p(t)}{d t}=I \alpha p(t)+k_{21}(t)(1-p(t))$

where $\alpha$ is the coefficient of extinction, which is practically independent of $I$ in the experimentally studied interval of light intensities (at most $20 \mathrm{~W} / \mathrm{m}^{2}$ ). In this case, the coefficient $k_{21}$ should be determined with the help of Eq. (8). We also additionally assumed $[5,7]$ that the coefficient of extinction does not depend on time. Thus, specific features of the kinetics of $\mathrm{RC}$ are described in the model under consideration with the help of the modeling of the rate of inverse transitions. We assume that this quantity depends on time. Hence, we consider $k_{21}(t)$.

The processes running in the $\mathrm{RC}$ complex at the switching-out of light are described by Eq. (19), for which the initial condition takes the form

$p(t=0)=p_{0}$,

where the parameter $p_{0}$ describes the probability of the presence of electrons at the donor at the time moment of the switching-out of exciting light and depends on its intensity, the dependence of the exciting light intensity on the time, and the temperature of a specimen.

\section{Specimens, Results of Measurements, and Their Discussion}

In the present work, we used the isolated proteinpigment complexes (RCs) separated at the Chair of Biophysics of Lomonosov Moscow State University from the photosynthetic membranes of Rhodobacter sphaeroides cells by using a detergent lauryldimethylaminooxide (LDAO). To ensure the long-term stability of the parameters of $\mathrm{RC}$, we used a water solution of $0.01 \mathrm{M}$ sodium-phosphate buffer at $\mathrm{pH} 7.2$ with the addition of $0.05 \%$ detergent. The measuring cuvette was $3 \times 5 \times 2.5 \mathrm{~cm}$ in size with quartz walls of $1 \mathrm{~mm}$ in thickness.

The solution of RCs with a concentration of $\sim 10^{-6} \mathrm{M}$ was held in dark at room temperature for at least $12 \mathrm{~h}$ (dark-adapted state). The light-adapted state was formed under the illumination of the solution of RCs with a light pulse with varying duration and intensity [1-7]. The spectral range of an exciting light-emitting diode overlapped the most part of the absorption band of the RC "antenna". The relative number of centers and the transition rate from one state to another one were determined from the kinetics of the optical absorption spectrum at $\lambda_{0}=865 \mathrm{~nm}$ with the use of Eq. (19).

The results of measurements are illustrated by Figs. 1 and 2, where we show the recovery kinet- 
ics of the absorption of RCs after the switching-out $(t=0)$ of exciting light $(865 \mathrm{~nm})$ with various intensities and durations. It is seen from the data that, after the switching-out of exciting light, the absorption of RCs approaches a stationary regime in $10 \mathrm{~s}$. The jump of the values $\left(A_{(t=0)} \div A_{(t>10 s)}\right)$ increases with the exposure of RCs. The results of processing of experimental data with the use of relation (18) are given in Fig. 2, where the kinetics of the relaxation rate constant $k_{21}(t)$ of RCs to the dark-adapted state after the switching-out of exciting light with various intensities and durations is presented. This allows us to draw the following conclusions:

1) for the first $0.1 \div 2 \mathrm{~s}$, the value of $k_{21}(t)$ is maximal and slightly varies in the course of time. After the termination of this time interval, the value of $k_{21}(t)$ decreases by $2 \div 3$ orders for $\sim 1 \div 3$ s and then remains constant, $k_{21}$. This fact testifies to the invariability of properties of RCs in this time interval;

2) an increase of the exposure duration of a specimen by exciting light or an increase of its intensity leads to a decrease of the parameter $k_{21}$.

Such a dependence of the relaxation rate constant $k_{21}(t)$ of RCs on the time can be a consequence of the peculiarities of polarization effects in a vicinity of $\mathrm{Q}_{B}$ due to viscoelastic properties of the environment. In order to obtain the information directly about the transition rate constants in RCs with the help of experimental data on $k_{21}(t)$, we use formula (18) and the assumption that the transition of an electron from $\mathbf{Q}_{D}$ directly onto donor $\mathbf{P}$ is strongly suppressed, and, therefore, we can set $k_{B P}=0$. In this case, the following relation is true:

$k_{21}(t)=\frac{k_{A P} k_{B A}}{k_{A B}}$.

According to the literature data [4-7], the rate constant $k_{A P}$ does not depend on the time, and, therefore, the kinetics of $k_{21}(t)$ is completely determined by the rate constants $k_{B A}$ and $k_{A B}$ of the transitions of an electron between quinones $\mathbf{Q}_{A}$ and $\mathbf{Q}_{B}$.

\section{Model for $k_{21}(t)$ in the Dark State}

To explain the indicated peculiarities of the behavior of $k_{21}(t)$, we propose a model which accounts for the established relations between experimentally measured quantities and is schematically presented in Fig. 3. In this figure, we also show the potential energies of the quinone molecules $\mathbf{Q}_{A}$ and $\mathbf{Q}_{B}$,

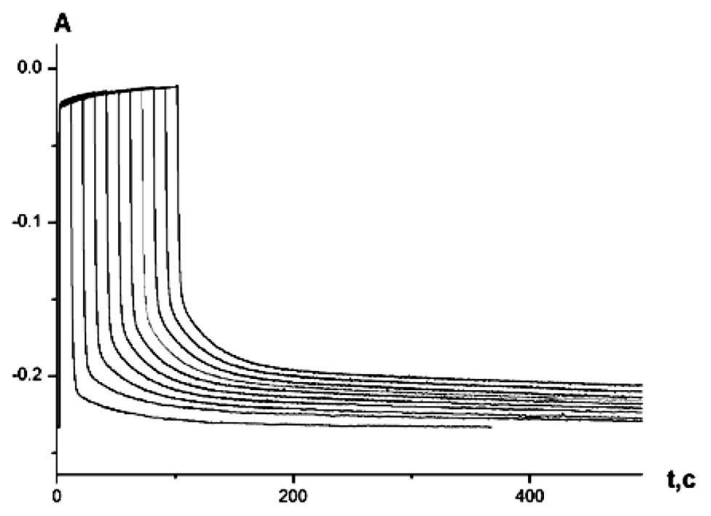

Fig. 1. Experimental data on the absorption of a water solution of RC complexes separated from the photosynthetic membranes of Rhodobacter sphaeroides cells after the switching-out of exciting light at the time moment $t=0$ at various exposures $(1,5,10,20,30,40,50,60,90,120,300,600 \mathrm{~s})$. The higher exposure durations correspond to higher positioned curves

between which the electron transfer is realized. The abscissa axis is the generalized nuclear coordinate (y) describing the position of the nuclei of atoms belonging to the composition of the corresponding quinone. During the presence of an electron at a quinone, the local electronic and orientational components of the polarization of the environment are created under the action of the electric field. These components determine the potential energy of the corresponding quinone [2]. The high-frequency component of the electronic polarization of the environment with frequency greater than the characteristic one of the electron transfer goes automatically after the electron under its transfer. Therefore, at the electron transfer, the orientational polarization of the environment different from the previous one must appear in vicinities of $\mathbf{Q}_{A}$ and $\mathbf{Q}_{B}$. In accordance with the Marcus model $[2,9]$, we assume that the polarization of the environment in the initial state can be randomly varied and shifted in the course of the fluctuation motion of the nuclei of quinone molecules to the direction of the polarization corresponding to the reaction products. This changes the potential energy of the corresponding quinones and allows the electron transfer to occur. The energy profile in Fig. 3 arises due to the quasiintersection of two potential curves corresponding to the orientational ordering of molecules of the environment around the initial complex and the reaction products. If the system attains the point, where the potential curves intersect, there occurs the 


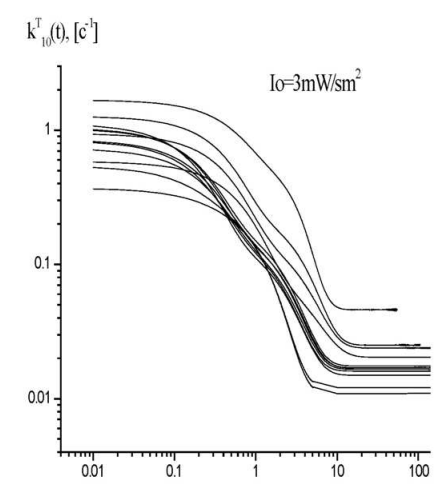

$a$

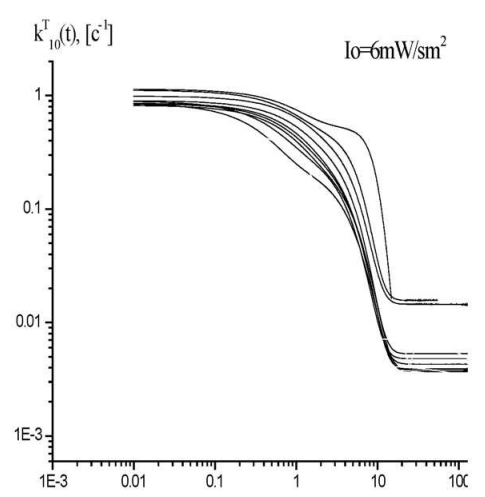

$b$

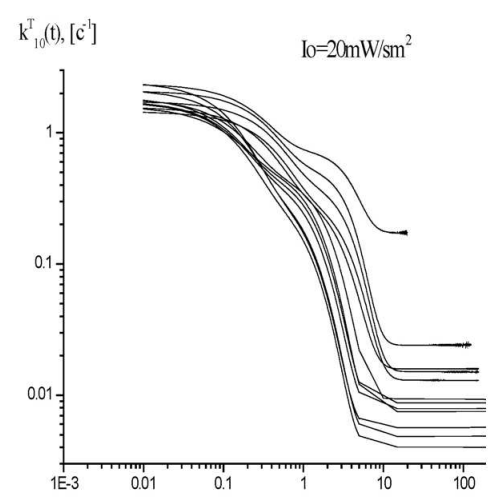

c

Fig. 2. Temporal variation of the absorption of a water solution of RC complexes after the switching-out $(t=0)$ of exciting light for various exposures $(1,5,10,20,30,40,50,60,90,120,300,600 \mathrm{~s})$ and $I_{0}=3,6,20\left[\mathrm{~mW} / \mathrm{cm}^{2}\right]$. The less exposure durations correspond to higher positioned curves

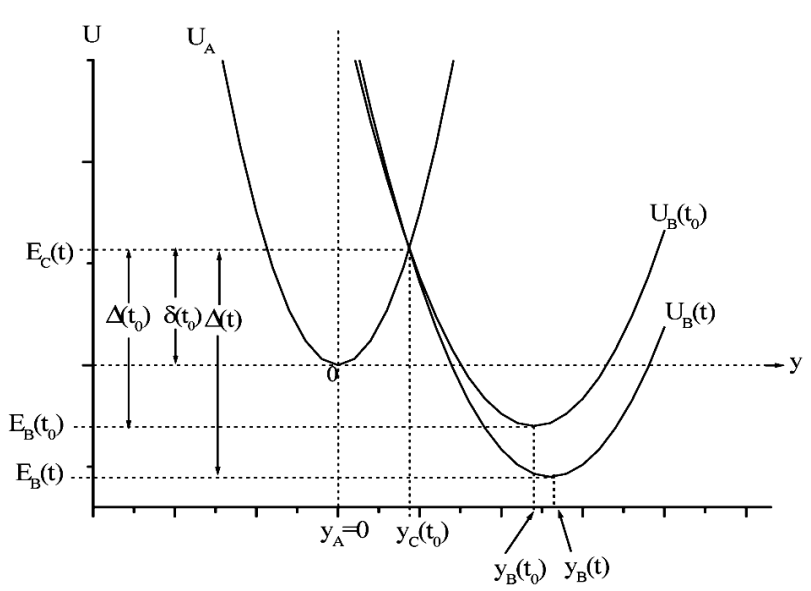

Fig. 3. Scheme of the electron transitions between quinones $\mathbf{Q}_{A}$ and $\mathbf{Q}_{B}$. Plots of the function $U_{B}(\mathrm{y})$ are given for two time moments $\left(t=t_{0}\right.$ is the time moment of the switching-out of light, and $\left.t>t_{0}\right)$. The heights of the potential barriers $\Delta$ and $\delta$ hampering the transitions of the electron $\mathbf{Q}_{B} \rightarrow \mathbf{Q}_{A}$ and $\mathbf{Q}_{A} \rightarrow \mathbf{Q}_{B}$ depend on time

instantaneous electron transfer. Let the potential energy $U_{A}(y)$ of quinone $\mathbf{Q}_{A}$ attain the minimum at the point $y=0$. For simplicity, we assume that the function $U_{A}(y)$ has $[2,5,8]$ parabolic character:

$U_{A}(y)=\frac{\chi}{2} y^{2}$.

Here, $\chi$ is the parameter, which defines the steepness of branches of the potential $U_{A}(y)$ and depends on the parameters defining the dynamics of polarization processes (e.g., on local rheological characteristics of the environment). We assume that the potential energy $U_{B}(y)$ of quinone $\mathbf{Q}_{B}$ is described by a formula analogous to $(22)$ with regard for the fact that the nuclear coordinate of the secondary quinone is shifted and is located at the point we denote by $y_{B}$ :

$U_{B}(y)=\frac{\chi_{B}}{2}\left(y-y_{B}\right)^{2}-E_{B}$

The sense of the parameter $\chi_{B}$ is analogous to that of $\chi$. The quantity $E_{B}$ sets the minimum value of the potential energy of the $\mathbf{Q}_{B}$ molecule. We also assume that the nearest environment of $\mathbf{Q}_{B}$ is not toughly fixed [2], and, on the appearance of an electron on the secondary quinone, its polarization varies in time due to the Coulomb forces. This must imply that the quantities $\chi_{B}, y_{B}$, and $E_{B}$ turn out to be dependent on the time. The assumption made is partially supported by experiments on the measuring of the volume of RCs present in the solution [7]. Indeed, the volume of RCs decreases by $2 \div 4 \%$ under the action of light. For simplicity, we suppose that $\chi=\chi_{B}$, and only $y_{B}(t)$ and $E_{B}(t)$ depend on the time. As the important parameters of the model, we indicate the characteristics $\left(y_{C}(t), E_{C}(t)\right)$ of the point of quasiintersection of the curves $U_{A}(y)$ and $U_{B}(y)$ (Fig. 3)

$$
\begin{aligned}
& y_{C}(t)=\frac{a y_{B}^{2}(t)-2 E_{B}(t)}{2 a y_{B}(t)}, \\
& E_{C}(t)=\frac{\chi}{2} y_{C}^{2}(t) .
\end{aligned}
$$

ISSN 2071-0194. Ukr. J. Phys. 2016. Vol. 61, No. 10 
In the frame of the proposed model, the quantities $y_{C}(t)$ and $E_{C}(t)$ reveal the nontrivial dependence on the time caused by the polarization processes leading also to the dependences $y_{B}(t)$ and $E_{B}(t)$. Let us assume [2] that the environment of $\mathbf{Q}_{B}$ is characterized by viscosity and elasticity. In this case, if an electron gets into $\mathbf{Q}_{B}$ (the probability of the presence of an electron is $\left.q_{B}(t)\right)$, then there occurs a polarization of the environment under the action of the electric field of the electron, which changes its potential energy. We assume that the rate of variation of the potential energy of the electron is proportional to the probability of its presence at $\mathbf{Q}_{B}$ (by $\mu$, we denote the corresponding coefficient of proportionality). Once the electron leaves the level of $\mathbf{Q}_{B}$, it begins to relax to the initial state. We assume, first, that the rate of this process increases with a deviation of the level from its value $E_{B}^{0}$ at the time moment of the switching-on of exciting light and, second, the characteristic duration of relaxation $(\tau)$ is independent of this quantity. In such a case, the equation describing the dynamics of level 2 takes the form

$\frac{d E_{B}(t)}{d t}=-\mu q_{B}(t)-\left|\frac{E_{B}^{0}-E_{B}(t)}{\tau}\right|$.

Equation (26) should be supplemented by the initial condition

$E_{B}(t=0)=E_{B, 0}$,

where $E_{B, 0}$ is the value of the energy of $\mathbf{Q}_{B}$ at the time moment of the switching-out of exciting light $(t=0)$.

As for the possible dependence of $y_{B}(t)$, we assume, following work [10] and taking results in [6] into account, that the difference $\left(y_{B}^{0}-y_{B}(t)\right)$ is proportional to the quantity $\left|E_{B}^{0}-E_{B}(t)\right|$. Here, $y_{B}^{0}$ is the coordinate of $\mathbf{Q}_{B}$ in the equilibrium dark-adapted state. In this case, the following relation is valid:

$y_{B}^{0}-y_{B}(t)=\alpha\left|E_{B}^{0}-E_{B}(t)\right|$,

where $\alpha$ is the dimensional coefficient of proportionality.

Thus, relations (22)-(28) define the model of the temporal evolution of the potential energy of quinone $\mathbf{Q}_{B}$.

With the purpose to explain specific features of the kinetics of $k_{21}(t)$, we consider the peculiarities of the

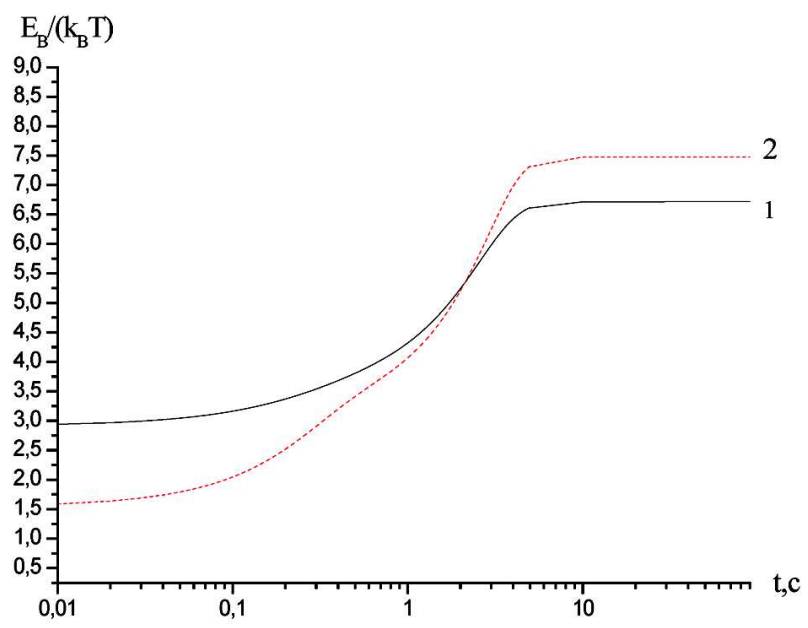

Fig. 4. Temporal behavior of the potential energy of the secondary quinone $\mathbf{Q}_{B}$ in the units of $k_{\mathrm{B}} T$ after the switchingout of exciting light at various values of its intensity (curve 1 is obtained at $3 \mathrm{~mW} / \mathrm{cm}^{2}$, and curve 2 at $20 \mathrm{~mW} / \mathrm{cm}^{2}$ ), the exposure duration is $300 \mathrm{~s}$

electron transitions $\mathbf{Q}_{B} \leftrightarrow \mathbf{Q}_{A}$. In Fig. 3, we present the scheme of the potential energies of quinones $\mathbf{Q}_{B}$ and $\mathbf{Q}_{A}$, by setting the characteristics of the electron transitions between them. Light is switched-out at the time moment $t_{0}=0$, and the time $t>t_{0}$ corresponds to the case where RC is in dark. By assuming the activation mechanism of overcoming the barrier separating the energy levels of electrons at quinones $\mathbf{Q}_{A}$ and $\mathbf{Q}_{B}[5]$, we note that the value of $k_{21}$ is determined by the height of this barrier $\Delta(t)$ according to the relation

$k_{B A}(t)=\nu \exp \left(-\frac{\Delta(t)}{k_{B} T}\right)$.

Here, $\nu$ is the frequency factor including the matrix element of the transition $\mathbf{Q}_{B} \rightarrow \mathbf{Q}_{A}, k_{\mathrm{B}}$ is the Boltzmann constant, and $\mathrm{T}$ is the temperature of a specimen. If the electron overcomes the barrier by the tunneling mechanism, relation (29) should be replaced by the relevant one from work [9]. The value of $k_{A B}$ is determined by the relation analogous to (29):

$k_{A B}(t)=\nu \exp \left(-\frac{\delta(t)}{k_{B} T}\right)$.

Here, the quantity $\delta$ (see Fig. 3) is the height of the energy barrier, which is overcome by the electron on the transition from quinone $\mathbf{Q}_{A}$ onto $\mathbf{Q}_{B}$. While deducing formulas (29) and (30), it was assumed that 
the electron transitions $\mathbf{Q}_{A} \leftrightarrow \mathbf{Q}_{B}$ occur by the activation mechanism; and we also take, to simplify the consideration, that the hopping frequencies of the electron for the transitions $\mathbf{Q}_{A} \rightarrow \mathbf{Q}_{B}$ and $\mathbf{Q}_{B} \rightarrow \mathbf{Q}_{A}$ are the same. Relations (22), (29), and (30) yield

$k_{21}(t)=k_{A P} \exp \left(-\frac{E_{B}(t)}{k_{B} T}\right)$.

We recall that $E_{B}(\mathrm{t})$ is the depth of the potential well, in which the electron is located during its presence at $\mathbf{Q}_{B}$, relative to the minimally possible value of the energy of the electron positioned at quinone $\mathbf{Q}_{A}$ (see Fig. 3). From relation (31), the experimental data given in Figs. 2-4, and the approximate relation $k_{A P} \sim 10 \mathrm{~s}^{-1}$, we can get the information about the kinetics of the electron level of $\mathbf{Q}_{B}$ relative to the electron level of $\mathbf{Q}_{A}$ :

$\frac{E_{B}(t)}{k_{B} T}=\ln \frac{10 s^{-1}}{k_{21}(t)}$.

The temporal behavior of $E_{B}(t)$ following from the data given in Fig. 2 is shown in Fig. 4.

\section{Conclusions}

1. We have established the essential dependence of the rate constant for the transition of the electron from the acceptor to the donor on the time after the switching-out of exciting light. This dependence has the $S$-like behavior. Such a dependence of $k_{21}(\mathrm{t})$ can be explained by a distortion of the electron level of the terminal acceptor $\mathbf{Q}_{B}$ as a result of polarization effects under multiple photoinduced transitions of the electron in the $\mathrm{RC}$ macromolecule.

2 . During the first $0.1 \div 2 \mathrm{~s}$, the value of the transition rate constant of electrons is maximal and depends slightly on the time. After this time interval, the constant decreases by $2 \div 3$ orders for approximately $3 \mathrm{~s}$. Then the value of the transition rate constant of electrons remains invariable, which testifies to the stability of properties of RCs in this time interval.

3. We have developed a theoretical model, which describes the transition of electrons $2 \rightarrow 1$ with regard for the possibility for polarization processes to occur in a vicinity of level 2 . These processes are running under the action of ponderomotive forces of the electric origin due to the field of the electron located on level 2. It is assumed that the peculiarities of the formation of a polarized environment of level 2 can be described with regard for its local viscosity and elasticity. The model considers the possibility for the distance between the levels to be changed under a variation of the polarization of level 2, which can be an analog of a variation of the conformational variable. The model explains qualitatively the experimental regularities of the relevant kinetics and describes specific features of the temporal variation of the rate constant for the transition of electrons from the acceptor onto the donor when the exciting light is switched-out.

4. We have found the unique combination of the transition rate constants for $\mathrm{RC}$ with the help of the analysis of the experimental data on the behavior of RCs after the switching-out of light and have determined the kinetics of the electron level of quinone $\mathbf{Q}_{B}$ relative to the level of quinone $\mathbf{Q}_{A}$.

1. J.M. Olson and J.P. Trornber, Membrane Proteins in Energy Transduction (Marcel Dekker, New York, 1999).

2. A.B. Rubin, Biophysics (Moscow State Univ., Moscow, 2000), Vol. 2 (in Russian).

3. M. Amin, L. Vogt, S. Vassiliev, I. Rivalta, M.M. Sultan, D. Bruce, G.W. Brudvig, V.S. Batista, and M.R. Gunner, Electrostatic effects on proton coupled electron transfer in oxomanganese complexes inspired by the oxygen-evolving complex of photosystem II, J. Phys. Chem. 117, 6217 (2013) [DOI: $10.1021 / \mathrm{jp} 403321 \mathrm{~b}$.

4. V.N. Kharkyanen, Yu.M. Barabash, N.M. Berezetskaya, E.P. Lukashev, P.P. Knox, and L.N. Christophorov, Peculiarities of light-induced slow protein dynamics in the photosynthetic reaction center, Chem. Phys. Lett. 512, Nos. 1-3, 113 (2011) [DOI: 10.1016/j.cplett.2011.07.006].

5. Yu.M. Barabash, N.M. Berezetskaya, L.N. Christophorov, A.O. Goushcha, and V.N. Kharkyanen, Effects of structural memory in protein reactions, J. Chem. Phys. 116, No. 10, 4339 (2002) [DOI: 10.1063/1.1447906].

6. A.K. Kukushkin and A.N. Tikhonov, Lectures on Biophysics of Photosynthesis (Moscow State Univ., Moscow, 1988) (in Russian).

7. Yu.M. Barabash, M.A. Zabolotny, N.I. Sokolov, and V.N. Kharkyanen, Slow photoinduced changes in reaction centers of Rhodobacter sphaeroides R-26 by holographic interferometry, Biofiz. 47, No. 6, 970 (2002).

8. A.O. Goushcha, M.T. Kapoustina, V.N. Kharkyanen, and A.R. Holzwarth, Nonlinear dynamic processes in an ensemble of photosynthetic reaction centers. Theory and experiment, J. Phys. Chem. B 101, No. 38, 7612 (1997) [DOI: $10.1021 /$ jp970868k].

9. V.I. Gol'dansky, L.I. Trakhtenberg, and V.N. Flerov, Tunneling Phenomena in Chemical Physics, (Nauka, Moscow, 1986) (in Russian).

Received 05.04.16 
Ю.М. Барабаш, М.А. Драпіковсъкий,

М.А. Заболотний, М.П. Куліш, О.П. Дмитренко

ДОСЛІДЖЕННЯ КІНЕТИКИ

ФОТОІНДУКОВАНИХ ЕЛЕКТРОННИХ ПЕРЕХОДІВ

В НАНОСТРУКТУРАХ БАКТЕРІАЛЬНИХ

\section{РЕАКЦІЙНИХ ЦЕНТРІВ}

$\mathrm{P}$ е $з$ ю м е

Досліджена повільна динаміка ізольованих комплексів хлорофілвмісних мембранних білків фотосинтетичних реакційних центрів (РЦ) Rb. Sphaeroides R-26, індукована потоками світла. Проведено аналіз зміни поглинання розчину РЦ в рамках трирівневої моделі. Встановлено рівняння, яке ви- значає відношення заселеності електронних рівнів первинного і вторинного хінонів. Розв'язок цього рівняння навіть у стаціонарному випадку має небольцманівський характер і залежить від інтенсивності збуджуючого світла. Запропоновано модель динаміки рівнів моделі РЦ, яка враховує можливість процесів поляризації в околі вторинного хінона $\mathbf{Q}_{B}$. Припускається, що всі РЦ мають тотожну структуру, але можуть знаходитись в різних станах, характеристики котрих залежать від часу, який пройшов після поглинання кванта світла, а також від локальної в'язкості і пружності середовища $\mathbf{Q}_{B}$. Із наявності деформаційних властивостей середовища навколо $\mathbf{Q}_{B}$ випливає, що конформація РЦ може змінюватися, що узгоджується із даними експерименту. 